\title{
Escolaridade, Salários e Empregabilidade: Tem Razão a Teoria do Capital Humano?
}

\author{
Moisés Balassiano \\ Alexandre Alves de Seabra \\ Ana Heloisa Lemos
}

\section{Resumo}

A teoria do capital humano e a discussão contemporânea acerca da empregabilidade abordam os impactos do capital educacional nas práticas produtivas dos indivíduos numa estrutura socioeconômica capitalista. O discurso corrente sobre essa relação tende a valorizar os efeitos da escolaridade diante da renda obtida pelos trabalhadores e das suas chances de inserção no mercado de trabalho. Este trabalho analisa estatisticamente as relações entre escolaridade, salário e empregabilidade pela perspectiva de um modelo estrutural, visando avaliar premissas da teoria do capital humano e da empregabilidade numa situação concreta. Para isso foi utilizada a base de dados da Relação Anual de Informações Sociais (Rais) do Ministério do Trabalho e do Emprego, com informação sobre os indivíduos que se encontravam no mercado formal de trabalho na Região Metropolitana do Rio de Janeiro em 1999. Os resultados mostraram que o impacto da escolaridade no nível de salário e na empregabilidade deve ser visto com ressalvas.

Palavras-chave: teoria do capital humano; empregabilidade; mercado de trabalho; modelo de equações estruturais.

\begin{abstract}
Both the human capital theory and the contemporary discussion of the employability approach the actual impacts of the education capital on the productive practices of people in a capitalist socioeconomic society. The main stream of this relationship tends to emphasize the education effects in the income received by the workers, as well as their chances to get into and remain in the work market. The present paper statistically analyses the relationships between education, wages and employability under the perspective of a structural equation model, in order to compare and to contrast both theories, using real data. Rais dataset, with information of the subjects working in the formal work market in the metropolitan area of Rio de Janeiro in 1999 was used to test the model. The results revealed that the impact of the education on wages and employability should be regarded with some caution.
\end{abstract}

Key words: human capital; employability; work market; structural equation model. 


\section{INTRODUÇÃO}

O debate contemporâneo sobre o desemprego e a reestruturação produtiva tem sido pautado, por um lado, por interpretações que valorizam premissas subjacentes à teoria do capital humano e ao discurso que valoriza a empregabilidade - herdeiro direto dessa teoria - e, por outro, por críticas e questionamentos a essas mesmas premissas. Apesar de estar no centro das discussões, pressupostos da teoria do capital humano vêm sendo pouco explorados em termos analíticos, pois são insuficientes os estudos capazes de apresentar evidências empíricas que comprovem ou contestem a crença de que a educação formal aumenta os rendimentos individuais. O mesmo ocorre em relação à idéia de que investimentos nessa área potenciam as chances de inserção dos indivíduos no mercado de trabalho.

A percepção da carência de estudos empíricos motivou a realização deste trabalho que visa testar a principal premissa da teoria do capital humano - o impacto positivo da educação formal (escolaridade) na renda dos trabalhadores - bem como o pressuposto de que esta aumenta as chances de obtenção de emprego. Para isso utilizamos o modelo analítico proposto por Seabra (2002) para responder às seguintes indagações:

. A escolaridade tem impacto direto positivo na renda do trabalhador?

- Quais os efeitos diretos e indiretos da escolaridade nas chances de se conseguir emprego (empregabilidade) e na renda do trabalhador?

. Existem outras variáveis intervenientes nas relações entre escolaridade, salário e empregabilidade?

Visando responder a essas indagações, o presente trabalho foi estruturado de modo a, primeiramente, reconstituir o contexto discursivo de valorização da teoria do capital humano e da empregabilidade. Em seguida, explicitar os aspectos metodológicos da análise realizada, apresentando o modelo utilizado e a consolidação dos resultados. E, finalmente, apresentar as principais conclusões.

\section{Teoria do Capital humano, Reestruturação Produtiva e Empregabilidade: Aspectos do Debate}

O processo de reestruturação produtiva atualmente em curso tem provocado 
mudanças significativas na forma como se organiza o mercado de trabalho, mudanças que têm criado um cenário de crescimento dos índices de desemprego aberto e de precariedade do emprego ${ }^{(1)}$. Essas transformações têm aparecido na discussão sobre a crise do mercado de trabalho, na qual se engajam estudiosos de diferentes orientações teóricas.

Apesar da crise do emprego ser o tema comum na maior parte das formulações contemporâneas acerca do mercado de trabalho, estas não convergem quando se trata de apontar as causas e, conseqüentemente, as saídas para o problema. Para autores como Rifkin (1995) e Castel (1998), a reestruturação produtiva - à medida que permite que se produza mais, com menos mão-de-obra - é a principal responsável pelo decréscimo da oferta de postos de trabalho. Por sua vez, Pochmann (2001) vê na associação entre reestruturação produtiva e globalização econômica a principal causa do desemprego, notadamente nos países periféricos. Uma terceira vertente - representada no Brasil por economistas como Alves (1997), Amadeo (1998), Barros et al. (2001), e Neri, Camargo e Reis (1999) atribui a responsabilidade pelo crescente desemprego à conjugação da reestruturação produtiva com o despreparo dos trabalhadores para assumir os novos postos de trabalho.

Não obstante a controvérsia em torno das implicações da reestruturação produtiva e seu impacto sobre o nível de emprego, constata-se que, no caso brasileiro, uma vertente se vem constituindo como importante orientadora da discussão pública sobre o desemprego: é aquela que atribui a responsabilidade pelo agravamento do problema à inadequada qualificação da mão-de-obra para assumir os novos postos de trabalho. Essa é a versão com mais visibilidade na mídia, além de ser orientadora da política pública de maior abrangência, elaborada nos últimos anos pelo Ministério do Trabalho e Emprego (MTE) para enfrentar essa situação: o Plano Nacional de Qualificação do Trabalhador (Planfor) ${ }^{(2)}$.

O processo de valorização da formação profissional como estratégia para enfrentar o desemprego - difundida no Brasil a partir da década de 1990 - é, em grande medida, um reflexo do debate internacional sobre a crise do mercado de trabalho. Essa é a interpretação que se torna corrente em países da União Européia, como Alemanha, Suécia, Inglaterra, Espanha, Itália, França e Holanda (DEDECCA, 1998); além de ser recomendação de organismos internacionais, como o Banco Mundial (1995), no tocante às políticas de combate ao desemprego. Por um lado, tal valorização reflete a retomada de pressupostos da teoria do capital humano, muito em voga na década de 1960 e, por outro, a crença na capacidade crescente do setor denominado nova economia de criar postos de trabalho mais sofisticados, que requerem profissionais mais bem qualificados. 
No que diz respeito à valorização da teoria do capital humano, o Relatório sobre o desenvolvimento mundial (BANCO MUNDIAL, 1995), ao defender a idéia de que as famílias devem investir em educação, como forma de valorizar seu capital humano, e ao atribuir o desenvolvimento das nações à qualidade desse capital, reproduz boa parte dos argumentos dessa teoria. No referido relatório há inúmeras passagens que parecem ter sido extraídas diretamente do livro de Schultz (1967), como a que afirma que "a educação é essencial para o aumento da produtividade individual", ou a que advoga que "a melhoria das aptidões e da capacidade do trabalhador é essencial para o êxito econômico numa economia global cada vez mais integrada e competitiva” (BANCO MUNDIAL, 1995, p. 42).

As premissas subjacentes à teoria do capital humano (SCHULTZ, 1967) também sustentam a valorização que a qualificação profissional vem recebendo no Brasil, nos últimos anos. É enfatizada a idéia de que o investimento em educação, ao aumentar a qualidade da força de trabalho, propicia ganhos de produtividade e o aumento da criação de postos de trabalho de melhor qualidade, conduzindo ao crescimento econômico. A percepção de que a educação é investimento e que a capacidade produtiva do trabalho é, em grande medida, um meio de produção originado - "Nós produzimos a nós mesmos" (SCHULTZ, 1967, p. 25) - reforça a preocupação com a qualificação do trabalhador, entendida como potenciadora do crescimento econômico e das chances individuais de acesso a melhores postos de trabalho. Logo, o capital educacional, acumulado pelo trabalhador, asseguraria não só sua maior produtividade, como explicaria as diferenças individuais de oportunidades de inserção no mercado e de remuneração recebida.

Valorizar a formação da força de trabalho como vetor de crescimento econômico e aumento da oferta de postos de trabalho é uma noção que se apóia em trabalhos de economistas, a maioria dos quais têm ou tiveram inserções em instituições e órgãos oficiais, que corroboram a tese de que a crise de desemprego contemporânea aponta a necessidade de investimentos em formação profissional.

Camargo e Almeida (1994), ao analisarem a relação entre investimento em capital humano e pobreza, e Soares e Gonzaga (1997), em estudo sobre a influência da escolaridade na determinação dos salários da força de trabalho brasileira, reeditam a discussão da teoria do capital humano que atribui as diferenças salariais dos trabalhadores aos seus diferentes níveis de instrução, constituintes de seu capital humano. Para discutir a relevância do investimento em políticas de qualificação da força de trabalho, como forma de diminuir a desigualdade de renda no Brasil, os autores testam um modelo que visa verificar a hipótese de segmentação ou dualidade do mercado de trabalho brasileiro. A 
existência de segmentação, entendida como condição na qual trabalhadores com idênticos níveis de qualificação recebem salários diferentes, seria uma restrição para o investimento em políticas de qualificação profissional e indicaria a necessidade de valorizar políticas que atuam sobre a demanda da força de trabalho, tanto em termos qualitativos como quantitativos. No entanto a conclusão do estudo aponta a não existência de dualidade ou segmentação no mercado de trabalho brasileiro, o que, segundo os autores, "faz crer que a educação é um determinante básico do salário e do acesso aos bons postos de trabalho no Brasil” (SOARES; GONZAGA, 1997, p. 3). Segundo os autores, a carência de qualificação básica de parte significativa da força de trabalho de países em desenvolvimento explicaria o retorno positivo do investimento em educação nesses países, tanto em termos salariais quanto de produtividade.

A valorização da educação, como estratégia para diminuir a desigualdade social no Brasil, também está presente no trabalho de Ferreira (2000) que, tendo como ponto de partida as diferentes correntes econômicas explicativas da elevada desigualdade brasileira, busca identificar a que melhor responde ao problema. Sem desconsiderar fatores como segmentação do mercado (setorial, regional e formal/informal) e discriminação (gênero e raça) - ambos influentes no processo de formação de renda do trabalho - o autor ressalta que o impacto da educação acumulada pelo trabalhador sobre a renda percebida é significativamente superior aos demais fatores. Sendo assim, os desníveis educacionais seriam os principais responsáveis pelos desníveis de renda e, conseqüentemente, pela desigualdade social, o que reforça a valorização de políticas que visam aumentar o nível educacional da população brasileira. Segundo Ferreira (2000, p. 24) “a evidência empírica sugere fortemente que a educação continua sendo a variável de maior poder explicativo para a desigualdade brasileira”.

Esse conjunto de argumentos, além de garantir a revalorização dos pressupostos da teoria do capital humano, vem servindo de fundamento para a principal categoria contemporânea a explicar e apresentar soluções para o problema do desemprego: a empregabilidade.

A premissa de que o capital educacional do trabalhador garantiria empregos de melhor qualidade e remuneração fundamenta a valorização crescente que a categoria empregabilidade vem recebendo nos últimos anos. Conceito em construção, a empregabilidade do trabalhador é definida por Cardoso, Caruso e Castro (1997, p. 12) como a "capacidade de preservar a ocupação atual (num ambiente onde se instabilizam os requerimentos vis-à-vis à mão-de-obra) ou, mesmo, de vir a reempregar-se (...) em caso de perda do emprego".

A empregabilidade vem sendo diretamente associada à questão da qualificação profissional, sendo esta representada por um conjunto de atributos que incluem 
aspectos relativos à educação formal, à capacidade de aprender permanentemente, de empreender, além de um conjunto de atitudes como iniciativa, autonomia e versatilidade. Esses atributos garantiriam aos trabalhadores a decantada empregabilidade, isto é, a capacidade de permanecer no mercado de trabalho.

Valorizada no meio empresarial e na literatura voltada para o mundo dos negócios, a empregabilidade é herdeira dos pressupostos da teoria do capital humano, na medida em que atribui à educação e qualificação profissional o papel fundamental para se enfrentar os desafios impostos pela reestruturação produtiva, a saber: a necessidade de trabalhadores mais qualificados e produtivos. No contexto que combina modernização tecnológica, ganhos crescentes de produtividade e redução dos postos de trabalho, a empregabilidade é encarada como a solução para os problemas atuais do mundo do trabalho.

No estudo de Rodrigues (1998) sobre o pensamento pedagógico da Confederação Nacional da Indústria (CNI), a preocupação com a empregabilidade está implícita em boa parte dos documentos analisados pelo autor, ainda que a menção direta da expressão não seja freqüente. Ao defender os investimentos públicos e privados em educação básica e formação profissional, a CNI atribui a essas condições a competitividade dos indivíduos e, conseqüentemente, das empresas.

Apesar de valorizada na literatura produzida no âmbito empresarial, a categoria empregabilidade é questionada pela sociologia do trabalho e da educação. Educadores como Rodrigues (1997), Machado (1998), Gentili (2001) e Frigotto (2001) associam a empregabilidade ao enfoque economicista da educação, tributário da teoria do capital humano. Por esse motivo, criticam a instrumentalização da educação - tratada como a solução para os males da reestruturação produtiva - subjacente à noção de empregabilidade.

Para Machado (1998, p. 18), o “conceito de empregabilidade tem sido utilizado para referir-se às condições subjetivas da integração dos sujeitos à realidade atual dos mercados de trabalho e ao poder que possuem de negociar sua própria capacidade de trabalho". A autora associa o conceito à ideologia liberal, que pressupõe que os indivíduos são responsáveis pela sua posição no mercado de trabalho. Portanto, as chances e condições de inserção seriam condicionadas aos atributos individuais. É essa ideologia que estaria “consubstanciada no discurso da empregabilidade e da competência” (MACHADO, 1998, p. 19).

Por sua vez, Frigotto ressalta que, na década de 1960, a leitura economicista da educação remetia a uma perspectiva de integração social, na medida em que a tese do pleno emprego era subjacente à valorização do investimento em capital 
humano. A essa observação contrapõe o fato de que, nas circunstâncias atuais, "a educação formal e a qualificação são situadas como elementos da competitividade, reestruturação produtiva e da empregabilidade” (FRIGOTTO, 2001, p. 15). Partindo dessa perspectiva, a empregabilidade se refere à aposta na educação básica e na qualificação profissional como saídas para a crise de desemprego que afeta boa parte das economias capitalistas na atualidade. Essa aposta pressupõe investimentos em educação e formação profissional que “desenvolvam habilidades básicas no plano do conhecimento, das atitudes e dos valores, produzindo competências para gestão da qualidade e, conseqüentemente, para a empregabilidade” (FRIGOTTO, 2001, p. 45).

Além desses aspectos, o autor também identifica nesse conceito a tentativa de deslocar para o plano individual aquilo que, até recentemente, era responsabilidade social: o emprego. Na noção de empregabilidade está implícita a idéia de que o indivíduo é responsável pela própria formação e obtenção de trabalho. Para Frigotto (2001, p. 46), há uma violência ideológica nessa concepção, pois a valorização da formação profissional e a oferta da escola de qualidade total levam os indivíduos que não lograram obter trabalho a interpretarem seu insucesso como incompetência. Em outras palavras "as vítimas do sistema excludente viram algozes de si mesmas". Finalmente, acrescenta que é ilusório para países como o Brasil apostar no investimento em qualificação da força de trabalho como caminho para uma inserção favorável na economia globalizada, dado que outros condicionantes estruturais limitam as oportunidades de inserção.

Sociólogos como Cardoso (2000) também questionam a rationale subjacente à empregabilidade. $\mathrm{O}$ autor chama atenção para o fato de a empregabilidade ser uma categoria que, além de individualizar a questão da obtenção do emprego atribuindo o sucesso e o insucesso nessa empreitada aos ativos que o trabalhador é capaz de oferecer ao mercado de trabalho -, "se assenta sobre a desigualdade efetiva de distribuição de recursos ou ativos empregáveis entre os indivíduos trabalhadores" (CARDOSO, 2000, p. 61). O conceito de empregabilidade explica o desemprego em moldes análogos aos utilizados pela teoria do capital humano para explicar as diferenças de renda entre os indivíduos, isto é, “o desemprego decorre do fato de que determinados indivíduos (os desempregados) não investiram adequadamente em si mesmos para tornar sua força de trabalho atraente para os empregadores, como os outros indivíduos (os empregados) o fizeram" (CARDOSO, 2000, p. 63-64).

Ao elaborar a crítica interna aos pressupostos subjacentes à noção de empregabilidade, o autor destaca as inconsistências de um modelo que só garante êxito para aqueles que o adotam (isto é, investem em qualificação profissional) se seus concorrentes não fizerem o mesmo (o que invalidaria o investimento 
individual). Nesses termos, para funcionar, a teoria em estudo pressupõe que haja desigualdade e segmentação no mercado de trabalho, premissa essa incongruente com outro pressuposto da teoria, que é a tendência ao equilíbrio do mercado, devido à concorrência perfeita entre os indivíduos.

Valorizada por uns e criticada por outros, a categoria empregabilidade está presente no debate contemporâneo em torno do desemprego e da reestruturação produtiva. Conforme mencionado anteriormente, há muita discussão sobre seus pressupostos e implicações e poucos estudos empíricos fundamentando ou mesmo refutando a sua principal premissa, isto é, a noção de que o incremento da qualificação profissional resultará em aumento da empregabilidade individual. Essa constatação motivou a utilização do modelo analítico proposto por Seabra (2002) para orientar a investigação voltada para a obtenção de indicadores que permitissem avaliar os referidos pressupostos.

\section{A Construção de um Modelo de Análise de Dados sobre EMPREGABILIDADE}

A questão crucial da formulação de um modelo envolvendo pressupostos como os subjacentes à noção de empregabilidade e à teoria do capital humano diz respeito à definição dos indicadores que permitirão a sua operacionalização. Tendo em vista a impossibilidade de obtermos indicadores para atributos de difícil mensuração, como os que conformam o perfil do trabalhador empregável, por um lado, e a dificuldade de quantificar todos os conhecimentos que comporiam a educação de um indivíduo, por outro, optamos por utilizar o grau de escolaridade como uma proxis tanto para a educação, como para a qualificação profissional. Essa escolha decorre do fato de que a escolaridade é a única variável disponível na fonte dos dados sobre o assunto. Entretanto são reconhecidas as limitações de tal escolha, na medida em que não considera os outros atributos de empregabilidade, anteriormente mencionados, nem integra à concepção de educação os cursos não formais, como os de treinamento e capacitação. Não obstante essas limitações, acreditamos que, dada a importância da educação formal para a formação do trabalhador, as conclusões obtidas a partir da análise da escolaridade podem ser interpretadas à luz dos pressupostos das abordagens conceituais em exame.

\section{Base dos Dados}

Para realizar a investigação foram utilizadas, como base de dados, as estatísticas sobre empregos formais que constam do Cadastro Geral de Empregados e 
Desempregados (Caged) e da Relação Anual de Informações Sociais (Rais), ambas do Ministério do Trabalho e do Emprego, de 1999, na Região Metropolitana do Rio de Janeiro.

A população estudada foi a das pessoas empregadas no mercado formal, ou seja, os indivíduos que tinham vínculo empregatício com determinado estabelecimento. Foram levantados os dados dessa população entre janeiro de 1990 e dezembro de 1999. Definida a população, o período a ser estudado compreendeu o total de 120 meses, para permitir o entendimento da trajetória dos indivíduos no tempo. Se tivéssemos optado pelos indivíduos com vínculo em 1990, não haveria como distinguir se um indivíduo que saiu do mercado formal em 1991 e não retornou até 1999, havia efetivamente saído do mercado de trabalho (aposentadoria etc.) ou se estava desempregado. Para evitar esse problema, trabalhou-se com os indivíduos com vínculo em 1999, buscando seu histórico desde 1990.

O tempo total desses indivíduos no mercado formal começou, por definição, no mês e ano referentes à data de admissão em sua primeira aparição no período de 1990 a 1999. Mesmo que a data de admissão do indivíduo fosse anterior a janeiro de 1990, a contagem foi iniciada em janeiro de 1990, preservando, assim, o período a ser analisado (120 meses).

\section{Depuração dos Dados}

As informações recebidas continham, para cada indivíduo com vínculo empregatício em 1999, um histórico para cada vínculo, no qual estava registrado ano e mês da admissão e da demissão. Além desses dados, foram fornecidas, para cada ano, as remunerações médias em salários mínimos, o sexo, a subatividade em que o indivíduo atuava - de acordo com a classificação da Fundação Instituto Brasileiro de Geografia e Estatística (IBGE) -, o grau de instrução - tabulado conforme o manual da Rais/99 e apresentado na Tabela 1 e a faixa etária, conforme a Tabela 2.

\section{Extração dos Dados para um Arquivo de Trabalho}

O arquivo original recebido do Ministério do Trabalho e do Emprego continha mais de 3 milhões de registros, pois cada vínculo do indivíduo era representado por um registro com os valores correspondentes das variáveis relacionadas àquele vínculo. Foi desenvolvido um programa de computador para ler o arquivo original e criar um arquivo de trabalho, onde cada registro corresponderia a um indivíduo e seriam computadas as variáveis: tempo total no mercado, tempo de emprego, tempo de desemprego e empregabilidade para cada indivíduo da população; além 
de recolher as variáveis existentes, como sexo, grau de escolaridade, faixa etária etc. Esse novo arquivo continha um total de 2.589.366 registros. Definimos esse número como o tamanho da população a ser estudada, ou seja, o número de indivíduos que pertenciam ao mercado formal de empregos na Região Metropolitana do Rio de Janeiro em 1999.

\section{Definição das Variáveis}

Foram selecionados os seguintes indicadores para o estudo: escolaridade, idade, salário e empregabilidade. As variáveis representativas dos indicadores foram assim definidas:

- escolaridade - representada pelo grau de instrução, conforme definido na Tabela 1, correspondente à informação da Rais de 1999;

- salário - representado pela remuneração média. Foi utilizada a remuneração média correspondente ao ano de 1999, expressa em salários mínimos;

- idade - representada pela faixa etária, Tabela 2, e correspondente ao ano de 1999;

- empregabilidade - foi definida como a proporção entre o tempo em que o indivíduo esteve empregado (TE) e o tempo total em que o indivíduo esteve no mercado formal (TT), entre janeiro de 1990 e dezembro de 1999.

$$
\mathrm{E}_{\mathrm{i}}=\frac{\mathrm{TE}_{\mathrm{i}}}{\mathrm{TT}_{\mathrm{i}}}
$$

O tempo total em que o indivíduo esteve no mercado formal foi calculado por meio da contagem do número de meses entre a data da admissão (mês/ano) e a data da demissão (mês/ano) e ordenados os vínculos do indivíduo, do mais antigo ao mais recente, pela data da admissão. Assim, a avaliação do tempo total em que o indivíduo esteve no mercado formal obedeceu aos seguintes critérios:

- Caso a data da admissão fosse anterior a janeiro de 1990, o início do período foi fixado em janeiro de 1990.

. Caso o indivíduo tivesse, entre 1990 e 1999, apenas um vínculo, o tempo total calculado foi o número de meses da data de admissão até dezembro de 1999.

- Para o indivíduo cuja data da demissão foi anterior a dezembro de 1999, o 
período dessa data até dezembro de 1999 foi considerado como se ele estivesse no mercado formal de empregos. Cabe lembrar que, como a população foi definida como constituída por aqueles que tiveram vínculo empregatício em 1999, e que estamos estudando o seu histórico de 1990 a 1999, foi considerado que esse indivíduo ainda estava no mercado formal, apesar de desempregado em alguns meses finais de 1999.

- O tempo total máximo observado foi o período de 120 meses, correspondente ao tempo em que o indivíduo ingressou no mercado formal ou ao qual já pertencia em janeiro de 1990.

- No caso de quem teve mais de um vínculo empregatício, se houvesse coincidência de períodos, ou seja, se o indivíduo tivesse vínculo empregatício com dois estabelecimentos simultaneamente, ou trabalhasse em dois ou mais empregos simultaneamente, para efeito de contagem do tempo total, os meses coincidentes foram considerados como apenas um.

\section{Eliminação dos Dados Inconsistentes}

Analisados os registros do arquivo apresentado no item anterior, foram eliminadas algumas inconsistências, ou o que foi considerado falta de informação, como grau de escolaridade não informado ou os indivíduos que entraram no mercado formal em dezembro de 1999, o que equivale a uma contagem nula de tempo.

Identificados esses registros, num total de 200.469, optou-se pela sua simples eliminação, uma vez que se trabalhou com a população, e portanto sua eliminação não afetaria a significância da análise. Após a eliminação desses registros, permaneceram 2.388.897 indivíduos para a análise estatística.

\section{Modelo de Análise}

Visando avaliar os efeitos entre as variáveis de estudo, foi elaborado um modelo de relações estruturais, utilizando as variáveis do estudo, além de incorporada a idade como possível variável explicativa de salário e empregabilidade. Tal modelo pode ser expresso através do diagrama de caminho crítico, onde cada coeficiente representa o efeito de uma variável sobre outra, no sentido das setas que as unem. 


\section{Gráfico 1: Diagrama de Caminho Crítico do Modelo Proposto}

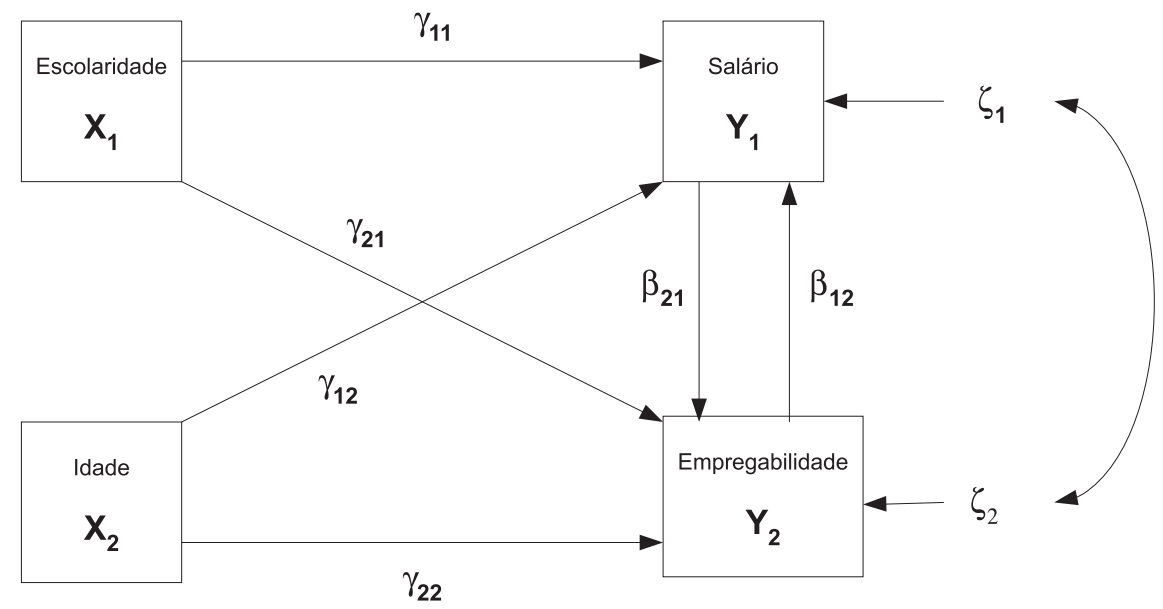

\section{Análise dos Resultados}

\section{Análise com Base nas Tabulações das Variáveis}

As tabulações apresentadas na análise dos dados, referentes à população, foram realizadas utilizando-se o Statistical Package for the Social Sciences (SPSS). Algumas tabulações foram exportadas para o aplicativo Excel, para a elaboração das figuras.

Através da Tabela 1 é possível verificar que, no mercado formal da Região Metropolitana do Rio de Janeiro, o contingente de menores de idade é praticamente nulo. A faixa dos 30 aos 49 anos representa mais da metade dos trabalhadores do mercado formal, e os indivíduos na faixa dos 30 anos representam, sozinhos, quase um terço da população total. A partir dos 65 anos, voltamos a ter um contingente mínimo na faixa de 1\%. Praticamente dois terços dos trabalhadores no mercado formal de empregos da região eram, em 1999, formados por indivíduos do sexo masculino, como podemos verificar na Tabela 2. 
Tabela 1: Distribuição dos Indivíduos no Mercado Formal da Região Metropolitana do Rio de Janeiro por Faixa Etária - 1999

\begin{tabular}{cccc}
\hline $\begin{array}{c}\text { Faixa } \\
\text { etária }\end{array}$ & $\begin{array}{c}\text { Período } \\
\text { (anos) }\end{array}$ & Frequiência & $\%$ \\
\hline 1 & 10 a 14 & 162 & 0,01 \\
\hline 2 & 15 a 17 & 15.444 & 0,65 \\
\hline 3 & 18 a 24 & 427.433 & 17,89 \\
\hline 4 & 25 a 29 & 398.995 & 16,70 \\
\hline 5 & 30 a 39 & 716.144 & 29,97 \\
\hline 6 & 40 a 49 & 535.074 & 22,40 \\
\hline 7 & 50 a 64 & 269.386 & 11,28 \\
\hline 8 & 65 ou mais & 26.259 & 1,10 \\
\hline \hline & Total & $\mathbf{2 . 3 8 8 . 8 9 7}$ & 100,00 \\
\hline \hline
\end{tabular}

Tabela 2: Distribuição dos Indivíduos, por Sexo, no Mercado Formal de Empregos da Região Metropolitana do Rio de Janeiro 1999 (Média Salarial em Salários Mínimos)

\begin{tabular}{lccc}
\hline \multicolumn{1}{c}{ Sexo } & Freqüência & $\%$ & $\begin{array}{l}\text { Salário } \\
\text { Médio }\end{array}$ \\
\hline Masculino & 1.500 .311 & 63 & 6,56 \\
\hline Feminino & 888.586 & 37 & 5,32 \\
\hline \hline Total & $\mathbf{2 . 3 8 8 . 8 9 7}$ & $\mathbf{1 0 0}$ & $\mathbf{6 , 1 0}$ \\
\hline \hline
\end{tabular}

O salário dos indivíduos do sexo masculino foram, em média, quase 25\% superiores ao dos indivíduos do sexo feminino.

Quanto à Tabela 3, esta apresenta a distribuição dos trabalhadores no mercado formal de empregos por nível de escolaridade. Nota-se que nos níveis de escolaridade incompleta existe uma diferença significativa, para menos, no número de indivíduos. Uma possível explicação para isso é que os indivíduos, ao ingressarem no mercado formal de emprego na Região Metropolitana do Rio de Janeiro, param de estudar e poucos são os que tentam melhorar a sua escolaridade. Apenas $12 \%$ dos indivíduos no mercado, que começaram a estudar nesse período, conseguiram concluir o curso superior. Esse percentual é compatível com a mesma estatística em nível nacional, que representava, em $2000,12,5 \%$. 
Tabela 3: Distribuição por Escolaridade dos Indivíduos no Mercado Formal de Empregos da Região Metropolitana do Rio de Janeiro - 1999

\begin{tabular}{|c|c|c|c|}
\hline Escolaridade & Nível & Freqüência & $\%$ \\
\hline $\begin{array}{l}\text { Analfabeto (incluindo quem, embora tenha recebido } \\
\text { instrução, não se alfabetizou) }\end{array}$ & 1 & 27.981 & 1,17 \\
\hline $\begin{array}{l}\text { Até a } 4^{\mathrm{a}} \text { série incompleta do } 1^{\circ} \text { grau ou que se tenha } \\
\text { alfabetizado sem ter freqüentado escola regular }\end{array}$ & 2 & 148.223 & 6,21 \\
\hline Com a $4^{\mathrm{a}}$ série completa do $1^{\mathrm{o}}$ grau & 3 & 332.109 & 13,90 \\
\hline Da $5^{\mathrm{a}}$ a $8^{\mathrm{a}}$ série incompleta do $1^{\circ}$ grau & 4 & 267.820 & 11,21 \\
\hline $1^{\circ}$ grau completo & 5 & 507.571 & 21,25 \\
\hline $2^{0}$ grau incompleto & 6 & 169.910 & 7,11 \\
\hline $2^{\circ}$ grau completo & 7 & 559.518 & 23,42 \\
\hline Superior incompleto & 8 & 92.532 & 3,87 \\
\hline Superior completo & 9 & 283.233 & 11,86 \\
\hline Total & & 2.388.897 & 100,00 \\
\hline
\end{tabular}

A Tabela 4 fornece as taxas de empregabilidade por nível de escolaridade. De acordo com os dados apresentados, é possível observar certa polaridade, com taxas mais elevadas nos extremos da distribuição. Isso sugere, pelo menos, duas observações. A primeira é que a relação entre escolaridade e empregabilidade -caso efetivamente venha a existir - não é linear, o que pode afetar os resultados do modelo, baseado na premissa da linearidade das relações entre as variáveis envolvidas. A segunda, e mais importante, é a falta de evidência do postulado segundo o qual a um aumento na educação (quando expressa pelo grau de escolaridade) corresponde um aumento na empregabilidade. É que as diferenças entre as taxas de empregabilidade são pouco significativas, levando em conta os diferentes graus de escolaridade, o que desautoriza considerações otimistas quanto à relevância da escolaridade para a empregabilidade.

\section{Tabela 4: Empregabilidade por Escolaridade no Mercado Formal de Empregos da Região Metropolitana do Rio de Janeiro - 1999}

\begin{tabular}{|c|c|c|}
\hline Escolaridade & Nível & Empregabilidade \\
\hline $\begin{array}{l}\text { Analfabeto (incluindo quem, embora tenha recebido } \\
\text { instrução, não se alfabetizou) }\end{array}$ & 1 & 0,9012 \\
\hline $\begin{array}{l}\text { Até a } 4^{\underline{a}} \text { série incompleta do } 1^{0} \text { grau ou que se tenha } \\
\text { alfabetizado sem ter freqüentado escola regular }\end{array}$ & 2 & 0,8842 \\
\hline Com a $4^{\mathrm{a}}$ série completa do $1^{0}$ grau & 3 & 0,8978 \\
\hline Da $5^{\mathrm{a}}$ a $8^{\mathrm{a}}$ série incompleta do $1^{\circ}$ grau & 4 & 0,8762 \\
\hline $1^{\circ}$ grau completo & 5 & 0,8854 \\
\hline $2^{0}$ grau incompleto & 6 & 0,8886 \\
\hline $2^{\underline{0}}$ grau completo & 7 & 0,9096 \\
\hline Superior incompleto & 8 & 0,9201 \\
\hline Superior completo & 9 & 0,9643 \\
\hline Geral & & 0,9028 \\
\hline
\end{tabular}


Na distribuição dos rendimentos médios por escolaridade, Tabela 5, podemos verificar que do nível 1 (analfabeto) até o nível 5 (primeiro grau completo) os salários médios não apresentam grandes diferenças, mas são ligeiramente decrescentes, ou seja, os salários não são sensíveis à escolaridade antes do segundo grau. A partir do segundo grau incompleto, ocorre aumento dos salários médios em progressão geométrica.

Tabela 5: Remuneração Média por Escolaridade no Mercado Formal de Empregos da Região Metropolitana do Rio de Janeiro - 1999 (Remuneração Média em Salários Mínimos)

\begin{tabular}{|c|c|c|}
\hline Escolaridade & Nível & $\begin{array}{c}\text { Remuneração } \\
\text { Média }\end{array}$ \\
\hline $\begin{array}{l}\text { Analfabeto (incluindo quem, embora tenha recebido } \\
\text { instrução, não se alfabetizou) }\end{array}$ & 1 & 3,94 \\
\hline $\begin{array}{l}\text { Até a } 4^{\underline{a}} \text { série incompleta do } 1^{\circ} \text { grau ou que se tenha } \\
\text { alfabetizado sem ter freqüentado escola regular }\end{array}$ & 2 & 4,27 \\
\hline Com a $4^{\mathrm{a}}$ série completa do $1^{\mathrm{o}}$ grau & 3 & 3,51 \\
\hline Da $5^{\mathrm{a}}$ a $8^{\mathrm{a}}$ série incompleta do $1^{\mathrm{o}}$ grau & 4 & 3,43 \\
\hline $1^{\circ}$ grau completo & 5 & 3,74 \\
\hline $2^{\underline{0}}$ grau incompleto & 6 & 4,36 \\
\hline $2^{-}$grau completo & 7 & 5,91 \\
\hline Superior incompleto & 8 & 9,95 \\
\hline Superior completo & 9 & 17,26 \\
\hline Geral & & 6,10 \\
\hline
\end{tabular}

Os resultados sugerem que a educação, quando expressa pela escolaridade, passa a exercer alguma influência sobre os salários, após o segundo grau. A partir daí, o aumento de um nível na escolaridade leva a aumentos mais do que proporcionais nos salários.

\section{Análise com os Resultados da Aplicação do Modelo}

O modelo de relações estruturais proposto por Seabra (2002) calcula os efeitos diretos, indiretos e totais das variáveis exógenas (escolaridade e idade) nas variáveis endógenas (salários e empregabilidade). Com base nos resultados obtidos, os efeitos são analisados na Tabela 6. 
Tabela 6: Efeitos Diretos Determinados pelo Modelo

\begin{tabular}{lccc}
\hline & \multicolumn{2}{c}{ Variáveis } & \\
\cline { 2 - 3 } Que causam efeito & \multicolumn{2}{c}{ Que sofrem o efeito } \\
\cline { 2 - 3 } Escolaridade & Salário & Empregabilidade \\
\hline Idade & 0,29 & 0,55 \\
\hline Salário & 0,05 & 0,46 \\
\hline Empregabilidade & - & $-1,20$ \\
\hline
\end{tabular}

Observando os efeitos apresentados na Tabela 6, a conclusão é a de que:

. O efeito direto da escolaridade na empregabilidade é quase o dobro do efeito no salário. Ambos são positivos, o que significa que um acréscimo no grau de escolaridade poderá resultar num efeito mais diretamente positivo na taxa de empregabilidade do que no salário do indivíduo.

- A idade pouco influencia diretamente o salário, tendo influência mais significativa na empregabilidade.

- O efeito direto de maior intensidade, determinado pelo modelo, é o efeito do salário sobre a empregabilidade, só que de forma negativa e com intensidade $20 \%$ superior. Isso significa que a taxa de empregabilidade do indivíduo tende a ser reduzida com a conquista de melhores salários.

- O efeito direto unitário da empregabilidade no salário foi atribuído no modelo, a fim de se fixar a escala dos efeitos. Desta forma, a ordem de grandeza dos demais efeitos estimados deve ser avaliada em relação a ele para fins de comparações.

A maior parte dos estudos sobre o tema analisa as relações diretas entre as variáveis envolvidas; contudo, muitas vezes, a intervenção de outros fatores pode potenciar ou mascarar influências não percebidas antecipadamente. Nesse sentido, com base no modelo, foram analisados os efeitos indiretos das variáveis exógenas sobre as endógenas. A Tabela 7 apresenta os valores estimados para esses efeitos. 


\section{Tabela 7: Efeitos Indiretos Determinados pelo Modelo}

\begin{tabular}{lccc}
\hline $\begin{array}{c}\text { Que causam o } \\
\text { efeito }\end{array}$ & Intervenientes & $\begin{array}{c}\text { Que sofrem o } \\
\text { efeito }\end{array}$ & Efeito indireto \\
\hline Escolaridade & Salário & Empregabilidade & $0,29 \cdot(-1,20)=\mathbf{- 0 , 3 5}$ \\
\hline Empregabilidade & Salário & $0,55 \cdot 1,00=\mathbf{0 , 5 5}$ \\
\hline Idade & Salário & Empregabilidade & $0,05 \cdot(-1,20)=\mathbf{- 0 , 0 6}$ \\
\hline & Empregabilidade & Salário & $0,46 \cdot 1,00=\mathbf{0 , 4 6}$ \\
\hline
\end{tabular}

A escolaridade tem efeito indiretamente negativo na empregabilidade, quando intermediada por salário; e positivo no salário, quando intermediada pela empregabilidade. O sentido dessas relações pode ser creditado ao efeito diretamente negativo do salário sobre a empregabilidade, isto é, a um aumento no salário verifica-se uma redução na empregabilidade dos indivíduos, como visto anteriormente. Conseqüentemente, a escolaridade, elevando o salário, levará a uma redução na empregabilidade da força de trabalho formal. No entanto, aumentando a escolaridade, verifica-se aumento na empregabilidade, que por sua vez levará ao aumento dos salários.

Na análise, ao ser incorporada a idade, nota-se que esta tem efeito indiretamente negativo sobre a empregabilidade, quando intermediada por salário, embora tal efeito seja residual; e positivo com salário, quando intermediado por empregabilidade, nesse caso, de forma mais contundente. Levando em conta esta última relação, que foi a mais intensa, podemos concluir que a maturidade somente representa um fator de aumento salarial, quando vista através da empregabilidade.

O modelo apresenta os efeitos totais, isto é, a soma dos efeitos diretos e indiretos das variáveis exógenas sobre as variáveis endógenas, demonstrados na Tabela 8. O efeito total da escolaridade sobre o salário é quatro vezes maior que o efeito total da escolaridade sobre a empregabilidade. Na mesma direção, o efeito total da idade sobre o salário aumenta em função da incorporação na análise da variável empregabilidade, mas pouco se altera sobre empregabilidade diante do baixo efeito da idade sobre o salário. A Tabela 8 apresenta os valores dos efeitos totais das variáveis exógenas nas endógenas.

Tabela 8: Efeitos Totais Determinados pelo Modelo

\begin{tabular}{|c|c|c|}
\hline \multicolumn{3}{|c|}{ Variáveis } \\
\hline \multirow[t]{2}{*}{ Que causam o efeito } & \multicolumn{2}{|c|}{ Que sofrem o efeito } \\
\hline & Salário & Empregabilidade \\
\hline Escolaridade & $0,55+0,29=0,84$ & $0,55-0,35=0,20$ \\
\hline Idade & $0,05+0,46=0,51$ & $0,46-0,06=0,40$ \\
\hline
\end{tabular}




\section{Conclusões}

Tendo como ponto de partida os pressupostos da teoria do capital humano na forma apresentada no presente trabalho, a análise elaborada procurou investigar as relações entre escolaridade, salário e empregabilidade, com a inserção da variável idade, ante os referidos pressupostos. Conforme anteriormente ressaltado, a falta de indicadores capazes de mensurar a educação, em seu sentido mais amplo, e a qualificação profissional, com todas as suas implicações, fez com se recorresse à variável escolaridade, pois esta é componente decisivo da educação e da qualificação dos indivíduos. Por conseguinte, as conclusões a serem formuladas devem ser interpretadas como respostas parciais às premissas subjacentes às referidas abordagens teóricas, tendo em vista que não contemplam os demais atributos que comporiam a educação e a qualificação. Ainda assim, essa limitação não invalida a importância dessas conclusões, pois os aspectos deixados de fora, por serem predominantemente intangíveis, não se prestam a análises quantitativas como as elaboradas.

Feitas essas ressalvas, a análise apresentada permite tecer as seguintes considerações.

- No que se refere ao impacto positivo do aumento da escolaridade na renda do trabalhador - premissa central da teoria do capital humano - é possível constatar, analisando a Tabela 5, um incremento significativo dos salários apenas para as faixas de maior escolaridade, a partir do segundo grau. Para os demais níveis, as diferenças, além de pouco significativas, apresentam uma reversão de expectativas, uma vez que o grupo com escolaridade baixa, até a quarta série incompleta do primeiro grau, recebe salários, em média, superiores ao extrato subseqüente, possuidor de maior educação formal. Apesar de, em termos gerais, percebermos efeito diretamente positivo da escolaridade no salário, a baixa relação linear entre essas duas variáveis permite afirmar apenas que o aumento na escolaridade irá resultar em incremento na renda apenas a quem tenha maior escolaridade.

. De acordo com a Tabela 4, os números que relacionam o impacto do nível de escolaridade na empregabilidade da população estudada indicam variações pouco significativas entre as taxas de empregabilidade para os diferentes graus de escolaridade. É digno de nota o fato do grupo sem escolaridade formal (analfabetos) apresentar a mesma taxa de empregabilidade do grupo que possui o segundo grau completo. A essa constatação acrescenta-se a de que não há diferenças sensíveis entre os três grupos de menor escolaridade (dos analfabetos até aqueles que completaram a quarta série do primeiro grau) e os que 
concluíram o segundo grau. Complementando essas observações, deve-se ressaltar que, observado o efeito total da escolaridade na empregabilidade, verifica-se a fragilidade dessa relação, quando comparada com as demais. Esse fato leva ao questionamento do pressuposto que permeia o discurso da empregabilidade - o de que o aumento da escolaridade, tendo em vista que esta representa maior qualidade da força de trabalho, aumentaria também sua empregabilidade. Sem desprezar a importância de investimentos na educação dos trabalhadores, não se pode, com base nos dados analisados, afirmar que o investimento em educação formal tem impacto significativo no quesito empregabilidade. Em outros termos, é possível afirmar que indivíduos com mais escolaridade não são, necessariamente, mais empregáveis.

. Ainda quanto ao impacto da escolaridade na empregabilidade dos trabalhadores, deve ser ressaltada a constatação de que o aumento do salário tem efeito negativo na empregabilidade dos indivíduos, fazendo com que a combinação escolaridade/salários elevados resulte em menos empregabilidade. Como não é combinação incomum, trabalhadores com maior escolaridade tendem a receber maiores salários, conforme mostrado neste estudo, é possível até mesmo postular que, em muitos casos, indivíduos com escolaridade elevada apresentam baixa empregabilidade, em decorrência do efeito indireto do salário nessa relação. Em relação à premissa central da teoria do capital humano, podemos considerar que, caso as premissas dessa teoria fossem totalmente verdadeiras, teríamos, no limite, trabalhadores mais bem remunerados, porém menos empregáveis.

Essas constatações fazem com que se veja com ressalvas os pressupostos subjacentes à teoria do capital humano (educação influenciando renda) e à noção de empregabilidade - a qualificação potenciando as chances de inserção e permanência dos indivíduos no mercado de trabalho - visto que as relações observadas, apesar de apresentarem efeitos positivos em certos casos, não podem ser vistas como evidências desses pressupostos. Pelo contrário, constatações como a de que o salário elevado reduz a empregabilidade dos indivíduos com maior escolaridade, por um lado, e a de que a escolaridade não tem efeito tão marcante sobre a renda nos levam a relativizar os pressupostos mencionados.

Além desses aspectos, pode-se acrescentar o fato da idade do indivíduo fator normalmente esquecido em discussões sobre empregabilidade - influenciar quase tão intensamente suas chances de obter trabalho quanto a escolaridade. Em outros termos, pode-se considerar que se a escolaridade tem efeito positivo sobre a empregabilidade, a idade também o tem. Finalmente, é importante destacar a necessidade de maiores estudos capazes de fornecer dados empíricos para o debate contemporâneo em torno da questão da empregabilidade; debate esse 
que, em face da escassez e da limitação de análises dessa natureza, pode ser considerado aberto.

Artigo recebido em 10.11.2003. Aprovado em 05.02.2004.

\title{
Notas
}

\begin{abstract}
${ }^{1}$ Castel (1998) identifica como sintomas da precarização do emprego o crescimento dos vínculos de trabalho instáveis, temporários ou intermitentes; a perda de direitos trabalhistas e a queda de remuneração.

${ }^{2}$ Implementado a partir de 1995, e financiado com recursos do Fundo de Amparo ao Trabalhador (FAT), o Planfor visa garantir oferta de qualificação profissional a parcelas crescentes da população economicamente ativa (PEA), tendo por objetivo contribuir para o aumento da produtividade do trabalho e a redução do desemprego e do subemprego.
\end{abstract}

\section{ReferênCIAS Bibliográficas}

AMADEO, E.

Dez pontos sobre a situação recente do mercado de trabalho. Brasília: Ministério do Trabalho, ago. 1998. (Notas sobre o mercado de trabalho, n. 5).

ALVES, E. L. G.;

VIEIRA, C.A. S.

Qualificação profissional: uma proposta de política pública. In: ALVES, E. L. G. (Org.). Modernização produtiva e relações de trabalho no Brasil: perspectivas de políticas públicas. Petrópolis, RJ: Vozes; Brasília, DF: Ipea, 1997. p. 63-91.

\section{BANCO MUNDIAL.}

Relatório sobre o desenvolvimento mundial 1995: o trabalhador e o processo de integração mundial. 1. ed. Washington, D.C., 1995. p. 11-132.
BARROS, R. P. de;

COSSIO, M. B.;

TELES, J. L.

A eficácia das políticas de trabalho e renda no combate à pobreza. In: VELLOSO, J. P. R. et al. (Coords.). Soluções para a questão do emprego

- Fórum Nacional. Rio de Janeiro: José Olympio, 2001. p. 59-125.

CAMARGO, J. M.;

ALMEIDA, $\mathrm{H}$.

Human capital investment and poverty. Rio de Janeiro: PUC-Rio, 1994. (Texto para discussão, n. 319).

CARDOSO, A.;

CARUSO, L. A.;

CASTRO, N.

Trajetórias ocupacionais, desemprego e empregabilidade. Há algo de novo na agenda dos estudos sociais do trabalho no Brasil. Contemporaneidade e Educação, Rio de Janeiro: IEC, ano 2, n.1, p.7-23, 1. sem. 1997. 
CARDOSO, A. M.

Economia x sociologia: eficiência ou democracia nas relações de trabalho? DADOS, Rio de Janeiro, v. 43, n. 1 p. 45-82, 2000.

CASTEL, R.

As metamorfoses da questão social: uma crônica do salariado. Petrópolis: Vozes, 1998.

\section{DEDECCA, C.}

Qualificação e formação profissional: algumas experiências européias. In: ENCONTRO. A Visão Empresarial e da Universidade do Plano Nacional de Educação Profissional. 1998, São Paulo. Anais... São Paulo: UNIEMP, 1998, v.2.

\section{FERREIRA, F.}

Os determinantes da desigualdade de renda no Brasil: luta de classes ou heterogeneidade educacional? Rio de Janeiro: PUC-Rio, fev. 2000. (Texto para discussão, n. 415).

\section{FRIGOTTO, G.}

Educação, crise do trabalho assalariado e do desenvolvimento: teorias em conflito. In: FRIGOTTO, G. (Org.). Educação e crise do trabalho: perspectivas de final de século. 5. ed. Petrópolis: Vozes, 2001. p. 25-54.

\section{GENTILI, P.}

Educar para o desemprego: a desintegração da promessa integradora. In: FRIGOTTO, G. (Org.). Educação e crise do trabalho: perspectivas de final de século. 5. ed. Petrópolis: Vozes, 2001. p. 76-99.

MACHADO, L. R. S.

Educação básica, empregabilidade e competência. Revista Trabalho e educação, Belo Horizonte: NETE/ FAE/UFMG, n. 3, p. 15-21, jan./jul. 1998.

NERI, M.;

CAMARGO, J. M.;

REIS, M. C.

Emprego e produtividade no Brasil na década de 90. Rio de Janeiro: PUC, out. 1999. (Texto para discussão, n. 405).

POCHMANN, $\mathrm{M}$.

O emprego na globalização. 1. ed. São Paulo: Boitempo Editorial, 2001.

\section{RODRIGUES, J.}

Da teoria do capital humano à empregabilidade: um ensaio sobre as crises do capital e a educação brasileira. Revista Trabalho e Educação, Belo Horizonte: NETE/ FAE/UFMG, n.2, p.215-230, ago./ dez.1997.

O moderno príncipe industrial: o pensamento pedagógico da CNI. Campinas, SP: Editora Autores Associados, 1998.

\section{RIFKIN, J.}

The end of work: the decline of global labor force and the post-market era. 2nd ed. New York: Tarcher, 1995.

SEABRA, A. A.

Escolaridade, salários e empregabilidade: implicações no mercado de empregos do Rio de Janeiro. 2002. 58 f. Dissertação (Mestrado) - Escola Brasileira de Administração Pública e de Empresas/Fundação Getulio Vargas, Rio de Janeiro. 
SCHULTZ, T.

O valor econômico da educação. 1. ed. Rio de Janeiro: Zahar, 1967.
SOARES, R. R.;

GONZAGA, G.

Determinação de salários no Brasil: dualidade ou não-linearidade no retorno à educação? Rio de Janeiro: IPEA, dez. 1997. (Texto para discussão, n.380). 